JUPIIS: Jurnal Pendidikan Ilmu-ilmu Sosial, 12 (2) (2020): 305-311 DOI: 10.24114 /iupiis.v12i2.16998

JUPIIS: Jurnal Pendidikan Ilmu-ilmu Sosial

Available online http://jurnal.unimed.ac.id/2012/index.php/jupiis

\title{
Perilaku Pemilih Etnik Aceh Dalam Pemilihan Kepala Daerah 2017 Kabupaten Aceh Barat Daya
}

\section{Behavior of Ethnic Aceh Voters in 2017 Regional Election of Southwest Aceh District}

\author{
Robbi Sugara, Pujiati \& Ichwan Azhari
}

Program Pasca Sarjana Antropologi Sosial Universitas Negeri Medan, Indonesia

Diterima: 05 Februari 2020; Disetujui: 12 Mei 2020; Dipublish: 31 Desember 2020 \begin{abstract}
Abstrak
Tulisan ini bertujuan untuk mengetahui tentang perilaku pemilih etnik Aceh dalam menentukan calon kepala daerah yang sesuai dengan harapan pemilih serta bentuk strategi yang digunakan para calon kepala daerah dalam mendapatkan simpati masyarakat Aceh Barat daya. Penelitian ini menggunakan metode etnografi. Teknik penelitian dengan wawancara mendalam dan observasi partisipasi terhadap tim kampanye, tokoh dan masyarakat dalam pelaksanaan Pilkada 2017. ari hasil penelitian, masyarakat memilih calon kepala daerah berdasarkan visi misi yang berhubungan dengan kesejahteraan sosial seperti, pemberdayaan masyarakat petani dengan pemotongan harga bibit dan pupuk, atau pemberian beasiswa terhadap anak yang kurang mampu. Dalam mendapatkan suara masyarakat Aceh Barat Daya, calon kepala daerah memiliki strategi menggunakan symbol budaya seperti pakaian adat, kopiah meukotop, rencong, agamai dan basis posko. Kemudian para calon juga memanfaatkan kelompok masyarakat seperti komunitas pengajian dan pemuda. Dengan strategi pendekatan symbol budaya dan kelompok masyarakat, para calon berharap mendapatkan suara masyarakat dan dapat memberikan pengetahuan kepada generasi muda tentang kesadaran terhadap nilai-nilai budaya Aceh yang ada di Kabupaten Aceh Barat Daya.
\end{abstract}

Kata Kunci: Perilaku Pemilih, Strategi Pemenangan dan Etnik Aceh

\section{Abstract}

This paper aims to find out about the behavior of Acehnese ethnic voters in determining regional head candidates in accordance with the expectations of voters and the form of strategies used by regional head candidates in gaining sympathy from the people of Southwest Aceh. This research uses ethnographic methods. Research techniques with indepth interviews and participatory observation of campaign teams, leaders and the community in the implementation of the 2017 elections. From the results of the study, the community chose regional head candidates based on vision and mission related to social welfare such as, empowering farming communities by cutting seed and fertilizer prices, or scholarships for underprivileged children. In getting the voices of the people of Southwest Aceh, prospective regional heads have strategies using cultural symbols such as traditional clothing, meukotop skullcaps, rencong, agamai and post bases. Then the candidates also make use of community groups such as the Koran and youth communities. With a strategy approach to cultural symbols and community groups, the candidates hope to gain the voice of the community and be able to provide knowledge to the younger generation about awareness of the cultural values of Aceh in the Southwest Aceh District.

Keywords: Voter Behavior, Acehnese Ethnic and Winning Strategies

How to Cite: Sugara, R., Pujiarti, Azhari, I., \& Harahap, Y.R. (2020). Perilaku Pemilih Etnik Aceh Dalam Pilkada 2017 Kabupaten Aceh Barat Daya. JUPIIS: Jurnal Pendidikan Ilmu-ilmu Sosial, 12 (2): 305-311. 


\section{PENDAHULUAN}

Pelaksanaan pemilihan kepala daerah secara langsung merupakan upaya untuk memperbaiki kehidupan demokrasi setelah terjadi pergantian rezim Orde Baru ke reformasi. Dalam rangka pelaksanaan pemilihan kepala daerah langsung, caloncalon pemimpin daerah akan menjadikan momentum pemilihan kepala daerah sebagai ajang untuk pembuktian diri dalam mengemban amanat rakyat, sekaligus menemukan calon-calon pemimpin daerah yang berintegritas dalam memimpin daerah (Abdillah, 2002). Pemilihan kepala daerah juga dapat berpeluang memperkenalkan calon kepala daerah yang memiliki kredibelitas di mata masyarakat daerah sekaligus menguatkan derajat legitimasi (Suharyanto, 2014; Damanik, 2018)

Seperti penelitian yang dilakukan Ginanjar Muda (2010) mahasiswa dari Universitas Sumatra Utara (USU) dengan judul Perilaku Pemilih dalam Pilkada studi kasus: Etnis Karo di Desa Ketaren, Kecamatan Kabanjahe, Kabupaten Karo. Hasil penelitiannya menjelaskan bahwa Pemilihan Umum Kepala Daerah Karo merupakan salah satu PemilihanUmum Kepala Daerah yang terselenggara secara dua putaran, ada suatu keunikan tersendiri pada Pemilihan Umum Kepala Daerah Kabupaten Karo yaitu pasangan calon Kepala Daerah dan Wakil Kepala Daerah yang pada pemilihan putaran pertama mendapatkan suara terbanyak kemudian kalah pada pemilihan putaran kedua.

Fenomena politik yang terjadi di Kabupaten Karo dapat dianalisis dengan menggunakan pendekatan perilaku atau untuk lebih tepatnya perilaku pemilih. Pemilihan kepala daerah langsung dapat memperluas jaringan masyarakat lokal untuk mempengaruhi proses pengambilan keputusan yang menyangkut kepentingan rakyat di daerah Faraidiany, et.al., 2019; Suhardi. Et al., 2019; Khalehar, et al., 2017; Darmila, et al., 2019; Amin, \& Sembiring, 2018; Sembiring, et al., 2018). Masyarakat tersebut berkesempatan untuk terlibat dalam mempengaruhi pembuatan kebijakan publik yang dilakukan kepala daerah sebagaimana janjinya saat kampanye dan ikut pula mengawasi kepala daerah jika menyalahgunakan kekuasaan sehingga proses ini dapat memaksa kepala daerah untuk tetap memperhatikan aspirasi rakyat (Zega, Muda, Batubara \& Suharyanto, 2018; Syafitri, Muda \& Matondang, 2019).

Jaringan masyarakat lokal tersebut merupakan kelompok masyarakat yang sengaja di bentuk oleh calon-calon kepala daerah untuk memperkenalkannya kepada masyarakat. Jaringan masyarakat lokal inilah yang mengatur dan bersentuhan dengan masyarakat pemilih, serta yang menyambungkan antara aspirasi rakyat dan kebijakan publik oleh masing-masing calon (Abdullah, 2007).

Dalam arti jaringan masyarakat local merupakan tim sukses yang dibentuk calon kepala daerah. Untuk mendapatkan suara dalam pemilihan kepala daerah, tim sukses yang mengusung calon masingmasing memiliki cara untuk mendapatkan suara, baik memanfaatkan symbol etnis, berusaha memberikan kesadaran akan satu etnis dengan calon kepala daerah dan motif-motif budaya sebagai nilai jual pada saat pelaksanaan kampanye beserta program kandidat. Seperti Penelitian yang dilakukan Puspasari (2012) dari Universitas Sultan Ageng Serang, dengan judul Faktor-faktor yang mempengaruhi perilaku pemilih dalam pemilihan umum 
kepala daerah propinsi Banten tahun 2011 di Kecamatan Karawachi kota Tanggerang. Hasil penelitian menunjukan bahwa faktor kandidat mempunyai pengaruh tertinggi dalam perilaku pemilih, karena pemilih melihat kandidat dari citra suatu kandidat. Visi misi kandidat juga berpengaruh terhadap partisipasi pemilih, oleh karena itu dilakukan kampanye di berbagai daerah agar masyarakat Karawachi mengetahui program seorang kandidat

Pembentukan tim sukses atau pemenangan merupakan pemilihan orangorang yang dilakukan oleh orang kepercayaan yang disebut ketua tim dan ditunjuk langsung oleh calon kepala daerah. Pemilihan ketua tim sukses tidak lepas dari identitas dan pengetahuan tentang perilaku pemilih.

Rekruitmen yang dilakukan oleh ketua tim sukses tersebut, otomatis akan membuat pemecahan peta kekuasaan politik calon kepala daerah, karena akan berusaha menempatkan tim dalam setiap daerah pemilih, sehingga saudara, teman, bahkan keluarga akan terlibat konflik internal karena memiliki pandangan yang berbeda tentang calon-calon kepala daerah. Seperti pemilihan kepala daerah kabupaten Aceh Barat Daya (Abdya) pada 15 Februari 2017, meninggalkan konflik internal antara tim sukses pendukung calon tertentu sekaligus daerah-daerah yang tergolong basis-basis dari masingmasing calon.

Terlihat perbedaan antara tim sukses atau pendukung calon yang terpilih dan tidak terpilih, sehingga berdampak kepada kehidupan social mereka setelah selesainya pemilihan kepala daerah di Aceh Barat Daya.

\section{METODE PENELITIAN}

Metode penelitian ini menggunakan penelitian kualitatif dengan pendekatan Etnografi James P. Spradley. Teknik pengumpulan data menggunakan teknik wawancara secara mendalam, observasi partisipasi dan tradisi lisan. Etnografi ini memiliki sifat holistik-integratif, thick description, dan analisis kualitatif untuk mendapatkan native's point of view.

Metode ini didasarkan penelitian di kenal dengan nama, "Developmental Research Sequence atau Alur Penelitian Maju Bertahap, metode ini didasarkan atas 5 prinsip, yaitu teknik tunggal, identifikasi tugas, maju bertahap dan penelitian orisinal (Spradley, 1997). Langkah-langkah alur penelitian maju bertahap ini terdiri dari 12 langkah dan dimulai dengan suatu fokus yang luas pada langkah 1 sampai langkah ke 5 dan pada langkah ini adalah merupakan bagian dari analisis awal atau permukaan dari penelitian yang akan dikerjakan.

Kemudian mulai menyempit pada langkah ke 7 untuk penyelidikan intensif atas beberapa domain terpilih, lantas pada langkah ke 7 sampai 10 inilah menggunakan analisis yang mendalam (sistemis holistik) dan akhirnya pada langkah ke 11 dan 12 meluas kembali menjadi generalisasi (Spradley, 1997). Teknik pengumpulan data yang digunakan adalah observasi dan wawacara . Studi pustaka digunakan dalam pengumpulan data-data melalui sumber buku-buku, jurnal, tesis, desertasi dan media internet.

\section{HASIL DAN PEMBAHASAN}

Perilaku pemilih etnik Aceh yang menyebar di Kabupaten Aceh Barat Daya merupakan etnik Aceh yang masih mengedepankan kesamaan etnik dalam menentukan pilihannya. Pemilih etnik Aceh dalam pemilihan kepala daerah di 
Abdya masih melihat kandidat mana yang memiliki kesamaan etnik. Dengan melihat simbol budaya dan bahasa yang digunakan dalam membuat jargon kampanye. Biasanya etnik Aceh melihat pemakainan simbol budaya ataupun pakaian yang digunakan, karena dengan penggunaan simbol budaya tersebut, mereka serasa memilih saudara sendiri dan notaben tidak akan membuat program yang menyengsarakan masyarakat yang satu etnis.

Kesamaan identitas etnik ini yang dimanfaatkan oleh beberapa kandidat kepala daerah dalam menghimpun ataupun mendapatkan suara dari masyarakat luas, terutama masyarakat yang satu etnis dengan calon tersebut, maka disebarluaskan isu putra daerah dan orang kito. Terkadang program yang disampaikan oleh kandidat diluar etnik Aceh kurang diperhatikan, dengan melihat perilaku pemilih inilah para tim sukses selalu mendesain bentuk kampanye menggunakan bahasa daerah, pakaian dan symbol budaya.

Penggunaan pakaian adat yang dilakukan oleh kandidat dalam kampanye ataupun melalui Alat Peraga Kampanye (APK) dianggap sebagai cara kandidat untuk menjunjung nilai adat dan budaya etnik Aceh, sehingga unsur nilai-nilai keaceh-annya bisa dirasakan oleh masyarakat Aceh di Kabupaten Abdya

Dengan menggunakan pakaian adat berarti mencerminkan dan mengingat kembali budaya-budaya etnis pada zaman kerajaan, kesultanan dan pemangku Wali, yang pada akhirnya akan menaikkan semangat anggota maupun masyarakat seperti jargon lokal (peek semangat, pebedoh balek semangat yang awai-awai).
Para kandidat akan membentuk tim kampanye (Tim Sukses) yang dapat memanfaatkan primordialisme ini untuk menggiring pemikiran masyarakat etnik Aceh atau etnik lainnya agar memilih kandidat yang mereka dukung, biasanya kandidat yang didukung dari Partai lokal Aceh yang menjadi satu-satunya partai politik yang mengharuskan kandidatnya menggunakan pakaian adat dan urang kito.

Penggiringan opini yang dilakukan oleh tim sukses ini biasanya berhasil diterapkan di masyarakat luas, seperti sistem penyampain informasi yang paling sederhana dilakukan yaitu ketika salah seorang masyarakat ditanya oleh anggota masyarakat yang lain, akan memilih siapa saat pemilu nanti, maka ia akan menyebutkan "pileeh awak tanyoe nyang sok bajee adat Aceh (pilih orang kita yang menggunakan pakaian adat Aceh)" atau "Pileeh nyang sok Kupiyah Teuku Umar (Pilih yang menggunakan Kopyah Teuku Umar)". Sentimen-sentimen simbol-simbol seperti ini akan terus digulirkan hingga menjelang pelaksanaan pemilihan.

Setelah melakukan pencoblosan dari bilik suara, biasanya ada yang datang menghampiri anggota masyarakat tersebut dan bertanya kepadanya tentang siapa yang telah dipilih, maka anggota masyarakat tersebut akan menyebut "pileeh awak tanyoe". Pertanyaan itu datang dari anggota tim sukses yang telah ditugaskan menjaga setiap tempat pemungutan suara (TPS). Kalimat-kalimat seperti itu, tanpa disadari menjadi media kampanye yang sangat kuat. Dalam menentukan pilihannya, etnik Aceh memiliki standard nilai tersendiri, yaitu: 1) Primordialis (asal usul etnis); 2) Melihat kandidat calon yang peduli budayanya serta melestarikannya, ditandai dengan 
penggunaan pakaian adat dalam baliho atau APK; 3) Agamais; 4) Visi misi kampanye; 5) Track record

Pertarungan Pilkada di daerah Aceh Barat Daya yang dilaksanakan pada tahun 2017, terlihat beberapa calon memakai atribut keetnisan dalam menghimpun suara masyarakat, terkhusus suara etnik Aceh. Identitas keetnisan yang digunakan berupa simbol budaya, seperti kupiah, pakaian adat, bahkan penggunaan tradisitradisi yang masih berlaku di dalam masyarakat, hal ini dilakukan agar simpati masyarakat semakin mengalir untuk mendukung calon. Dengan memakai atribut simbol keetnisan, kandidat merasa lebih percaya diri dalam melaksanakan pemilihan kepala daerah.

Kehadiran simbol-simbol dalam kontestasi pemilihan kepala daerah berupa bendera, baliho, posko dan juga basis massa menjadi jauh lebih penting. Para Tim sukses juga melakukan pendekatan dengan masyarakat dan perangkat adat, guna menyambung lidah para kandidat untuk menyebarkan program yang akan dilaksanakan, selain itu, dengan menampilkan seni budaya Aceh Barat Daya, dekorasi lapangan kampanye, dan menghadirkan pemimpin yang berpengaruh atau karismatik akan semakin menambah rasa simpati masyarakat untuk memilih calon tertentu.

Disamping itu, perilaku pemilih etnik Aceh dalam memilih kandidat masih melihat tingkat keulamaan kandidat. Etnik Aceh dikenal dengan masyarakat yang agamais, khususnya Islam, dan sangat dekat dengan ulama. Eksistensi ulama bagi etnik Aceh menjadi panutan bagi segenap warga, sebagai sosok yang dihormati dan dikagumi, kekaguman masyarakat terhadap ulama, terutama karena mereka memiliki pengetahuan agama yang mendalam, ditambah lagi ulama juga sebagai tokoh yang memiliki kharismatik dalam kehidupan masyarakat. Seorang ulama dimata etnik Aceh bukan saja karena kesalehan dan ilmu, tetapi karena dipercaya sanggup memimpin masyarakat dan dapat menjadi pemersatu umat. Pada diri seorang ulama terpancar kharismatik yang menjadi satu kekuatan untuk menggerakkan dan memotivasi pemilih etnik Aceh untuk menentukan pilihannya.

Hal inilah yang dimanfaatkan kandidat untuk mendapatkan simpati etnik Aceh, yaitu dengan berpoto dengan ulama yang kemudian dipajang pada baliho-baliho, bahkan sering mengundang ulama-ulama tersebut untuk berceramah sekaligus mendeklarasikan dukungan kepada kandidat tersebut.

Para Tim sukses juga melakukan pendekatan dengan masyarakat dan perangkat adat, guna menyambung lidah para calon untuk menyebarkan program yang akan dilaksanakan oleh para calon, selain itu, dengan menampilkan seni budaya Aceh Barat Daya, dekorasi lapangan kampanye, dan menghadirkan pemimpin yang berpengaruh atau kharismatik, akan menambah rasa simpati pemilih etnik Aceh untuk memilih calon dari etnik Aceh.

\section{SIMPULAN}

Dalam pemilihan Kepala Daerah Aceh Barat Daya pada tahun 2017, terlihat perilaku pemilih etnik Aceh dalam memilih kandidat pilihannya, yaitu dengan melihat asal usul etnik, apabila dari etnik Aceh, maka akan dipilih. Disamping itu, pemilih etnik Aceh lebih simpati kepada calon yang menggunakan pakaian adat Aceh dan Kopyah Meukotop. Kemudian mereka lebih tertarik, apabila kandidat tersebut dekat dengan pemuka adat dan ulama, karena 
ulama merupakan panutan bagi pemilih etnik Aceh dan pilihan dari ulama pasti yang terbaik.

Dengan keadaan tersebut, maka para calon akan melakukan pendekatan primordial untuk mendapatkan suara dari pemilih khususnya etnik Aceh. Para tim sukses membuat kandidat menggunakan pakaian adat Aceh pada pelaksanaan kampanye, mendekorasi lapangan dengan simbol budaya etnik Aceh dan membuat poto baliho dengan gambar kandidat menggunakan pakaian adat Aceh lengkap dengan kopyah meukotop-nya. Untuk lebih menarik simpati pemilih etnik Aceh yang agamais, maka kandidat akan menggandeng ulama sebagai patron dalam pelaksanaan kampanye.

\section{UCAPAN TERIMAKASIH}

Ucapan terima kepada istri dan anakanaku tercinta yang memberi semnagat dan kasih sayangnya. Informan yang menyediakan waktunya diwawancarai baik masyarakat, tim sukses dan semua yang terlibat mengumpulkan data-data. Rekan-rekan PPS Antropologi Sosial Unimed yang banyak memberi masukan dalam penelitian ini.

Oleh karena itu kalimat ucapan Terima Kasih yang dalam kepada Bapak, Ibu dan kerabat sekalian, yang merupakan orang-orang yang sangat berperan dalam penyelesaian naskah penelitian ini.

\section{DAFTAR PUSTAKA}

Abdillah, U. 2002. Politik Identitas Etnis: Pergulatan Tanda Tanpa Identitas. Magelang: Indonesiatera.

Amin, M., \& Musthafa Sembiring, W. (2018). Local election: Does bureaucracy become one of main political power? In IOP Conference Series: Earth and Environmental Science (Vol. 126). Institute of Physics
Publishing. https://doi.org/10.1088/17551315/126/1/012097

Amirudin dan Bisri, A. Z. 2006. Pilkada Langsung: Problem dan Prospek (Sketsa Singkat Perjalanan Pilkada 2005). Yogyakarta: Pustaka Pelajar.

Bungin, B. 2012. Analisis Data Penelitian Kualitatif : wacana dan teoritis Penafsiran Teks. Jakarta: Raja Grafindo Persada.

Damanik, E.L (2018). Hashtag \#2019GantiPresiden: Sentimen Anti-petahana dan Orientasi Politik Pemilih Pemula menghadapi Pilpres 2019 di Pematangsiantar. JPPUMA: JPPUMA: Jurnal Ilmu Pemerintahan dan Sosial Politik UMA (Journal of Governance and Political UMA) UMA (Journal of Governance and Political Social UMA), 6 (2): 166-176.

Darmila, L. Ivanna, J. \& Iqbal, M. (2019) Perilaku Partisipasi Politik Masyarakat Desa Gunung Tua Tonga pada Pemilihan Bupati/Wakil Bupati Tahun 2013. PERSPEKTIF, 8 (2): 5871.

Faraidiany, M, Kusmanto, H. \& Warjio. (2019). Politik Identitas dalam Iklan Politik pada Pemilihan Kepala Daerah Sumatera Utara 2018, JUPIIS: Jurnal Pendidikan Ilmu-ilmu Sosial, 11 (1): 113-120

Friza. 2012. Political Explore. Sebuah Kajian Ilmu Politik. Bandung: Alfabeta.

Harjanto, N. 2011. Politik Kekerabatan dan Institusionalisasi Partai Politik di Indonesia. Analisis CSIS, 40 (2): 138-159.

Johnson, P. D. 1994. Teori Sosiologi: Klasik dan Modern. Jakarta: Gramedia.

Khalehar, M.F.A,, Ade A.J.S, Ivan S.Z., Prayetno, (2017), Perilaku Memilih Pemilih Pemula pada Proses Pemilihan Kepala Desa Laut Dendang Tahun 2016, Jurnal Pendidikan Ilmu-Ilmu Sosial, 9 (1): 99-101.

Koentjaraningrat. 2003. Pengantar Antropologi. Jakarta: PT Rineka Cipta.

Kurdi, M. 2005. Menelusuri Karakteristik Masyarakat Desa Pendekatan Sosiologi Budaya Dalam Masyarakat Aceh. Banda Aceh: Pena.

Muda, G. (2010), Perilaku Pemilih Dalam Pemilukada, Studi Kasus: Etnis Karo Di Desa Ketaren, Kecamatan Kabanjahe, Kabupaten Karo 2010. Thesis, FISIPOL, USU.

Muda, G. 2010. Perilaku Pemilih dalam Pilkada studi kasus: Etnis Karo di Desa Ketaren, Kecamatan Kabanjahe, Kabupaten Karo. Tesis. USU.

Musthafa Sembiring, W., Kusmanto, H., \& Siddik Pohan, Z. (2018). Recruitment Model Of Political Party For A Political Position In North Sumatera Province, Indonesia. Atlantis Press. https://doi.org/10.2991/icosop17.2018.101 


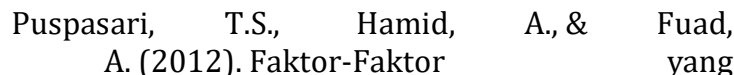
Mempengaruhi Perilaku Pemilih dalam Pemilihan Umum Kepala Daerah Provinsi Banten Tahun 2011 di Kecamatan Karawaci Kota Tangerang. Thesis, FISIP Untirta.

Spradley, P. James. 1997. Metode Etnografi. Yogyakarta: Tiara Wacana.

Suhardi. Nasution, M.A. \& Kusmanto, H. (2019). Partisipasi Pemilih dalam Pemilihan Umum Bupati/Wakil Bupati Langkat Tahun 2018. JUPIIS: Jurnal Pendidikan Ilmu-ilmu Sosial, 11 (2): 344-354.

Suharyanto, A., (2014). Partisipasi Politik Masyarakat Tionghoa dalam Pemilihan
Kepala Daerah, JPPUMA: Jurnal Ilmu Pemerintahan dan Sosial Politik UMA (Journal of Governance and Political UMA), 2 (2): 166-175

Syafitri, R. Muda, I. \& Matondang, A. (2019). Sistem Penerimaan Badan Ad Hoc Panitia Pemilihan Kecamatan dalam Pemilihan Kepala Daerah pada Komisi Pemilihan Umum Kota Medan. PERSPEKTIF, 8 (2): 72-76.

Zega, M.A. Muda, I. Batubara, B.M. \& Suharyanto, A. (2018). Pengaruh Program Rumah Pintar Pemilu Terhadap Partisipasi Politik Masyarakat Pada Kantor Komisi Pemilihan Umum Kota Medan, PERSPEKTIF, 7 (2): 6065 . 